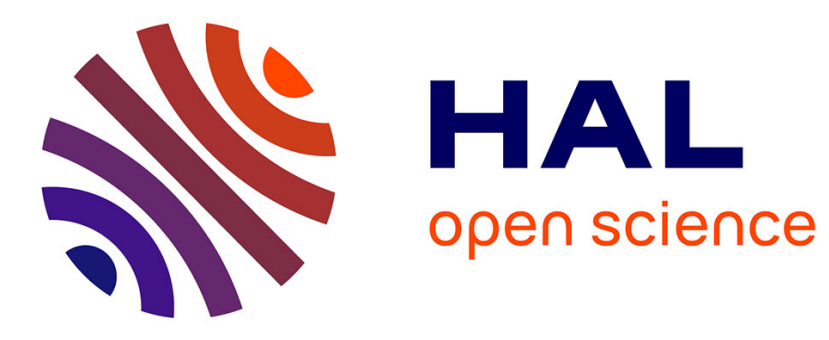

\title{
Health and welfare of organic pigs in Europe assessed with animal-based parameters
}

Sabine Dippel, Christine Leeb, Davide Bochicchio, Marianne Bonde, Klaas

Dietze, Stefan Gunnarsson, Kristina Lindgren, Albert Sundrum, Sofia Wiberg, Christoph Winckler, et al.

\section{To cite this version:}

Sabine Dippel, Christine Leeb, Davide Bochicchio, Marianne Bonde, Klaas Dietze, et al.. Health and welfare of organic pigs in Europe assessed with animal-based parameters. Organic Agriculture, 2014, 4 (2), pp.149-161. 10.1007/s13165-013-0041-3 . hal-01210399

\section{HAL Id: hal-01210399 \\ https://hal.science/hal-01210399}

Submitted on 27 May 2020

HAL is a multi-disciplinary open access archive for the deposit and dissemination of scientific research documents, whether they are published or not. The documents may come from teaching and research institutions in France or abroad, or from public or private research centers.
L'archive ouverte pluridisciplinaire HAL, est destinée au dépôt et à la diffusion de documents scientifiques de niveau recherche, publiés ou non, émanant des établissements d'enseignement et de recherche français ou étrangers, des laboratoires publics ou privés. 


\section{Health and welfare of organic pigs in Europe assessed with animal-based parameters}

\section{Sabine Dippel, Christine Leeb, Davide}

Bochicchio, Marianne Bonde, Klaas

\section{Dietze, Stefan Gunnarsson, Kristina} Lindgren, et al.

\section{Organic Agriculture}

Official journal of The International Society of Organic Agriculture Research

\section{ISSN 1879-4238}

\section{Volume 4}

Number 2

Org. Agr. (2014) 4:149-161

DOI 10.1007/s13165-013-0041-3

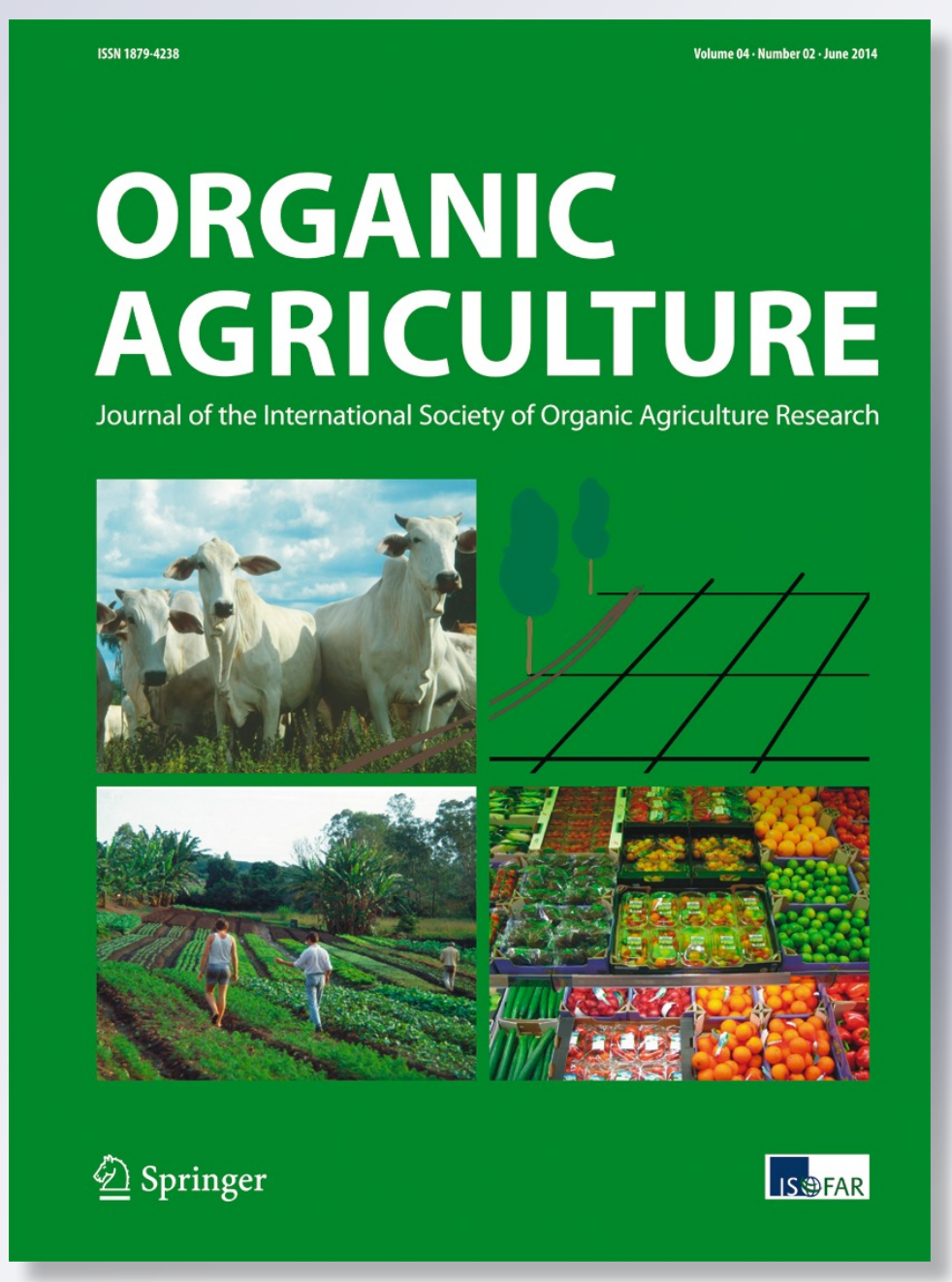

Springer 
Your article is protected by copyright and all rights are held exclusively by Springer Science +Business Media Dordrecht. This e-offprint is for personal use only and shall not be selfarchived in electronic repositories. If you wish to self-archive your article, please use the accepted manuscript version for posting on your own website. You may further deposit the accepted manuscript version in any repository, provided it is only made publicly available 12 months after official publication or later and provided acknowledgement is given to the original source of publication and a link is inserted to the published article on Springer's website. The link must be accompanied by the following text: "The final publication is available at link.springer.com". 


\title{
Health and welfare of organic pigs in Europe assessed with animal-based parameters
}

\author{
Sabine Dippel • Christine Leeb • Davide Bochicchio - Marianne Bonde • \\ Klaas Dietze • Stefan Gunnarsson • Kristina Lindgren • Albert Sundrum • \\ Sofia Wiberg • Christoph Winckler • Armelle Prunier
}

Received: 17 September 2012 / Accepted: 24 April 2013 /Published online: 8 May 2013

(C) Springer Science+Business Media Dordrecht 2013

\begin{abstract}
Organic pig farming aims at maintaining a high health and welfare state of the animals through appropriate housing, management and feeding. Better knowledge of health and welfare indicators should help to identify critical points and hence to improve health and welfare as well as performance of organic pigs. This paper describes the health and welfare of organic pigs from 101 farms across six EU countries, using selected animal-based parameters from the Welfare Quality ${ }^{\circledR}$ protocol. Parameters were collected in sows, suckling and weaned piglets in 3 to 20 farms per country. Their
\end{abstract}

\section{S. Dippel $(\bowtie)$}

Institute of Animal Welfare and Animal Husbandry,

Friedrich-Loeffler-Institut, Dörnbergstrasse 25/27, 29223

Celle, Germany

e-mail: sabine.dippel@fli.bund.de

S. Dippel $\cdot$ C. Leeb $\cdot$ C. Winckler

Division of Livestock Sciences, Department of Sustainable Agricultural Systems, University of Natural Resources and Life Sciences, Vienna (BOKU), Gregor-Mendel-Strasse 33, 1180 Wien, Austria

D. Bochicchio

Research Unit of Swine Husbandry (CRA-SUI),

Agricultural Research Council, 41018 San Cesario sul

Panaro, Modena, Italy

M. Bonde

Department of Animal Science, Aarhus University,

Box 50, 8830, Tjele, Denmark

\section{K. Dietze}

Animal Production and Health Division, Food and Agriculture Organization of the United Nations, Rome, Italy assessment was trained before farm visits and interobserver agreement determined after farm visits. The most prevalent problems identified in sows were thinness (median farm prevalence $18.8 \%$, range $0-81.0$ ), injuries on the anterior part of the body $(15.5 \%$, 0-66.7), injuries on hind part of body $(7.9 \%, 0-50)$, obesity $(4.9 \%, 0-50.0)$ and vulva lesions $(3.5 \%, 0-42.9)$. In suckling piglets, the median prevalence in terms of groups affected per farm was $0 \%$ for all parameters but '> $50 \%$ dirty piglets in group', for which it was $10 \%$. Farm prevalence ranged from 0 to $100 \%$ for ${ }^{\circ} \geq 1$

S. Gunnarsson $\cdot$ S. Wiberg

Department of Animal Environment and Health, SLU

(Swedish University of Agricultural Sciences),

P.O. Box 234, 53223 Skara, Sweden

K. Lindgren

Swedish Institute of Agricultural and Environmental

Engineering (JTI), Box 7033, 75007 Uppsala, Sweden

K. Dietze $\cdot$ A. Sundrum

Department of Animal Nutrition and Animal Health,

University of Kassel, Nordbahnhofstr. 1a,

37213 Witzenhausen, Germany

A. Prunier

UMR1348 PEGASE, INRA, 35590 Saint-Gilles, France

M. Bonde

Centre of Development for Outdoor Livestock Production, Marsvej 43, 8960 Randers, Denmark 
lame piglet in group', presence of diarrhoea, and '> $50 \%$ dirty piglets in group'. In weaned piglets, the median prevalence in terms of groups affected per farm was $0 \%$ with a range of 0 to $100 \%$ for all parameters. Based on the collected data, body condition, skin and vulva lesions in sows, lameness, diarrhoea and respiratory problems in piglets could be used as management and welfare indicators, with good potential for enhancement through farm improvement schemes like herd health planning. However, some definitions could be improved, especially lameness, diarrhoea and respiratory problems in piglets.

Keywords Sow - Suckling piglet · Weaned piglet . Inter-observer agreement $\cdot$ Monitoring $\cdot$ Status quo

\section{Introduction}

Organic pig production holds only small market shares, yet has received increased interest in Europe in recent years. One of the aims of organic agriculture is to assure good animal health and welfare, which should be achieved by species-appropriate housing conditions, as well as adequate management and feeding. As this is also expected by consumers (Harper and Makatouni 2002; Zanoli and Naspetti 2002), it is especially important to assess animal health and welfare in organic animal production.

Despite this need for documentation, there are only limited data available regarding health and welfare in organic pig production in the EU. In a survey of organic pig producers in UK, the most frequently reported problems were hepatic milk spots in finishing pigs, ectoparasites, mastitis and locomotory disorders in breeding stock (Day et al. 2003). Furthermore, in a questionnaire survey of organic sow farms in north-western Europe (Denmark, UK, Netherlands, Germany and Sweden), piglet mortality was perceived as a problem by $50 \%$ and weaning diarrhoea by $25 \%$ of the farmers (Bonde and Sorensen 2006). The health status of organic finishers has been compared to conventional finishers in Denmark, Germany and Sweden (Ebke and Sundrum 2005; Bonde et al. 2006; Heldmer et al. 2006). In comparison to conventional finishing pigs, organic finishers in Denmark had a higher prevalence of poor body condition and livers with milk spots, but had a lower prevalence of skin lesions and respiratory diseases (Bonde et al. 2006).
Clinical scoring of animals has been used widely in order to assess different aspects of animal health, because it is resource efficient and integrative (Meagher 2009). However, as clinical scoring is non-instrumental, the method can be criticised to have elements of subjectivity because each assessor has to rely on his/her judgemental abilities. Thus, there are three potential hazards to its reliability (i.e. repeatability) which need to be considered when planning data assessment using clinical scoring: quality of the score definitions, level of observer experience (with animals and with housing systems), and level of observer training (Meagher 2009).

The data presented in this paper are part of the ERAnet CORE Organic project COREPIG which had the aim of assessing and improving health and welfare in organic pigs (www.coreorganic.org/corepig). This publication describes the health and welfare of organic pigs across 6 EU countries, as assessed using selected animal-based parameters from the Welfare Quality ${ }^{\circledR}$ protocol.

\section{Methods}

Animal-based parameters

The animal-based parameters to be recorded were selected based on their indicative value for presence of health and welfare problems. Most of the parameters were scored based on the Welfare Quality ${ }^{\circledR}$ pig protocol (Welfare Quality ${ }^{\circledR} 2009$ ). They ranged from physiological indicators such as body condition, over indirect measures of behaviour (skin and vulva lesions) to management indicators such as dirtiness. For a complete list of scored parameters and their definitions, see Tables 1 and 2. Animals were scored in their normal housing environment, with the aim of scoring 30 gestating and 10 lactating sows, 10 litters and 5 groups of weaned piglets.

All parameters with scores 0,1 and 2 were dichotomised by grouping scores 1 and 2 into one score, because the prevalence of score 2 was very low in all parameters but dirtiness. Body condition was dichotomised by classifying scores 1 and 2 as 'thin' and scores 4 and 5 as 'fat'. Injury counts were also dichotomised by classifying zero and one lesion in the respective area as ' 0 ' and two and more lesions as ' 1 '. Furthermore, the areas ear, front and middle were combined into 'anterior', as the respective prevalences were 
Table 1 Scoring scales used for lactating and gestating sows. Scores 1 and 2 were combined for analysis

\begin{tabular}{|c|c|c|c|}
\hline & Score 0 & Score 1 & Score 2 \\
\hline Dirtiness ${ }^{a}$ & $\begin{array}{l}\text { Up to } 10 \% \text { of the body surface is } \\
\text { soiled }\end{array}$ & $\begin{array}{l}10 \text { to } 30 \% \text { of the body surface } \\
\text { is soiled }\end{array}$ & $\begin{array}{l}>30 \% \text { of the body surface is } \\
\text { soiled }\end{array}$ \\
\hline Body condition ${ }^{b}$ & Scores 1 (thin) to (5 fat) & & \\
\hline Injuries & $\begin{array}{l}\text { Counts of clearly visible lesions in } \\
\text { the five body regions ears, front, } \\
\text { middle, hind quarter, legs } \\
\text { (regions defined as in }{ }^{\mathrm{a}} \text { ); counted } \\
\text { at a distance of } 0.5 \text { to } 1 \mathrm{~m}\end{array}$ & & \\
\hline Skin condition ${ }^{a}$ & $\begin{array}{l}\text { No evidence of skin inflammation or } \\
\text { discolouration }\end{array}$ & $\begin{array}{l}<10 \% \text { of the skin is inflamed, } \\
\text { discoloured or spotted }\end{array}$ & $\begin{array}{l}>10 \% \text { of the skin is inflamed, } \\
\text { discoloured or spotted }\end{array}$ \\
\hline Vulva lesions ${ }^{a}$ & $\begin{array}{l}\text { No damage to the vulva, or small } \\
\text { lesions }(<2 \mathrm{~cm}) \text {, [or scar tissue } \\
\left.\text { visible; not in } \mathrm{WQ}^{\circledR}\right]\end{array}$ & $\begin{array}{l}\text { Injury visible, but in the } \\
\text { process of healing (scab or } \\
\text { crust formed), or a deformed } \\
\text { vulva }\end{array}$ & Any injury that is bleeding \\
\hline Lameness $^{\mathrm{a}}$ & $\begin{array}{l}\text { normal gait, or the animal has } \\
\text { difficulties walking but is still } \\
\text { using all its legs, the stride may be } \\
\text { shortened and/or there may be a } \\
\text { swagger of the caudal body when } \\
\text { walking }\end{array}$ & $\begin{array}{l}\text { The animal is severely lame- it } \\
\text { resists bearing weight on the } \\
\text { affected limb }\end{array}$ & $\begin{array}{l}\text { There is no weight bearing on } \\
\text { the affected limb, or the } \\
\text { animal is unable to walk }\end{array}$ \\
\hline Mastitis ${ }^{\text {a, c }}$ & No evidence of mastitis & - & $\begin{array}{l}\text { Inflammation of the udder } \\
\text { (and possibly thin piglets) }\end{array}$ \\
\hline Metritis ${ }^{a, c}$ & No evidence of a vulval discharge & - & Evidence of a vulval discharge \\
\hline Panting ${ }^{a}$ & No panting observed & - & Panting observed \\
\hline $\begin{array}{l}\text { Respiratory } \\
\text { problems }^{\text {a }}\end{array}$ & $\begin{array}{l}\text { No or one cough and / or sneeze } \\
\text { within } 5 \mathrm{~min}\end{array}$ & - & $\begin{array}{l}\text { More than one cough and/or } \\
\text { sneeze within } 5 \mathrm{~min}\end{array}$ \\
\hline Shortened tail & Tail has natural length & - & Tail shorter than natural \\
\hline Diarrhoea $^{\mathrm{a}}$ & Normal faeces & - & Liquid faeces present \\
\hline Solid faeces ${ }^{a, c}$ & Normal faeces & - & $\begin{array}{l}\text { Hard and solid faeces, similar } \\
\text { to rabbit droppings }\end{array}$ \\
\hline
\end{tabular}

${ }^{\text {a }}$ Welfare Quality ${ }^{\circledR}$ pig protocol (Welfare Quality ${ }^{\circledR}$ 2009)

${ }^{\mathrm{b}}$ MAFF (1998)

${ }^{\mathrm{c}}$ Lactating sows only

rather low and lesion causation in these areas is related (McGlone 1985).

\section{Inter-observer reliability (IOR)}

The observer who was the most experienced clinical pig assessor (CL) trained six other observers during 2 days, one on each of two farms, in February 2008. The observers had varying levels of pig expertise or experience with clinical scoring or housing conditions (indoor/outdoor). Training included parameter discussions and joint scoring of animals. One of the participating observers trained an additional observer in her home country, resulting in eight observers in total who collected data.
After completion of farm visits in July 2008 (see 'Farm survey' section below) observers were tested for inter-observer reliability. They scored up to 50 sows, 16 litters and 8 groups of weaners independently on one farm at the same day (for numbers of animals, see Tables 3 and 4).

Agreement was calculated pairwise as well as across all observers. For pairwise agreement in binary variables, we calculated prevalence adjusted bias adjusted kappa $(\mathrm{PABAK}=[(\mathrm{k} \times \mathrm{p})-1] /(\mathrm{k}-1)$, where $k=$ number of categories and $p=$ proportion of matchings between observers; Petersen et al. 2004). Agreement across observers was determined by calculating Kendall's Coefficient of Concordance ( $W$; MAGREE macro; SAS Institute Inc. 2009). Agreement for the non-binary lesion 
Table 2 Scoring scales used for suckling and weaned piglets. Scores 1 and 2 were combined for analysis. All definitions but 'runts' from Welfare Quality ${ }^{\circledR}$ pig protocol (2009)

\begin{tabular}{|c|c|c|c|}
\hline & 0 & 1 & 2 \\
\hline Dirtiness & $\begin{array}{l}\text { No pigs in the litter with } \\
\text { soiled body surface }\end{array}$ & $\begin{array}{l}\leq 50 \% \text { of piglets in the litter have a } \\
\text { soiled body surface }\end{array}$ & $\begin{array}{l}>50 \% \text { of piglets in the litter have a } \\
\text { soiled body surface }\end{array}$ \\
\hline Lameness & $\begin{array}{l}\text { All piglets in the litter } \\
\text { have a normal gait }\end{array}$ & $\begin{array}{l}1 \text { piglet in the litter displaying moderate } \\
\text { lameness (difficulties walking but still } \\
\text { using all of its limbs) }\end{array}$ & $\begin{array}{l}>1 \text { piglet in the litter displaying } \\
\text { moderate lameness, or } \geq 1 \text { piglet in } \\
\text { the litter displaying severe lameness } \\
\text { (minimum weight bearing on affected } \\
\text { limb; no weight bearing on affected } \\
\text { limb; unable to walk) }\end{array}$ \\
\hline Splay leg & $\begin{array}{l}\text { No pig in the litter with } \\
\text { splay legs }\end{array}$ & 1 pig in the litter with splay legs & $>1$ pig in the litter with splay legs \\
\hline Runts ${ }^{a}$ & Less than $5 \%$ & - & More than $5 \%$ \\
\hline Panting & No panting observed & - & Panting observed \\
\hline Respiratory problems & $\begin{array}{l}\text { No or one cough and / } \\
\text { or sneeze within } 5 \mathrm{~min}\end{array}$ & - & $\begin{array}{l}\text { More than one cough and/or sneeze } \\
\text { within } 5 \mathrm{~min}\end{array}$ \\
\hline Diarrhoea & Normal faeces & - & Liquid faeces present in pen \\
\hline
\end{tabular}

${ }^{\mathrm{a}}$ Runt $=$ pale piglet with a visible spine and hairy coat; scored in weaned piglets only

counts was determined using pairwise Spearman rank correlations (PROC CORR, option spearman). All calculations were performed with SAS 9.1.3 (SAS Institute Inc. 2008).
Average PABAK and $W$ were classified as follows: value $<0$ or at least one observer pair with PABAK $<0=$ poor agreement, $0-0.20=$ slight, $0.21-0.40=$ fair, $0.41-0.60=$ moderate, $0.61-0.80=$ substantial, and
Table 3 Inter-observer reliability of eight observers (data for injuries based on seven observers) for animal-based parameters in sows. Values represent mean (minimum-maximum) of observer pair values

$P A B A K$ prevalence adjusted bias adjusted kappa, n.a. insufficient data

\begin{tabular}{|c|c|c|c|c|}
\hline Parameter & Prevalence & PABAK & $\begin{array}{l}\text { Kendall's } \\
\text { W }\end{array}$ & $\begin{array}{l}N \text { sows } \\
\text { scored }\end{array}$ \\
\hline Fat sow & $0.08(0.04-0.13)$ & $0.83(0.71-1.00)$ & 0.59 & $45(41-49)$ \\
\hline Thin sow & $0.27(0.13-0.41)$ & $0.64(0.45-0.87)$ & 0.61 & $45(41-49)$ \\
\hline Dirty sow & $0.48(0.23-0.84)$ & $0.26(-0.38-0.59)$ & 0.43 & $46(41-50)$ \\
\hline $\begin{array}{l}\text { Sow has }>1 \text { injury } \\
\text { ear }+ \text { front }+ \text { middle }\end{array}$ & $0.40(0.14-0.53)$ & $0.53(0.07-0.82)$ & 0.64 & $44(40-49)$ \\
\hline Sow has $>1$ injury hind & $0.25(0.06-0.35)$ & $0.64(0.33-0.91)$ & 0.60 & $44(40-49)$ \\
\hline Sow has $>1$ injury legs & $0.28(0.06-0.43)$ & $0.53(0.22-0.88)$ & 0.54 & $46(41-50)$ \\
\hline Lame sow (scores $1+2)$ & $0.03(0.02-0.09)$ & $0.95(0.85-1.00)$ & 0.21 & $46(41-49)$ \\
\hline $\begin{array}{l}\text { Sow with mastitis } \\
\text { indication }\end{array}$ & $0.01(0.00-0.07)$ & $0.96(0.83-1.00)$ & 0.13 & $14(11-17)$ \\
\hline $\begin{array}{l}\text { Sow with metritis } \\
\text { indication }\end{array}$ & 0.00 & 1.00 & 1.00 & $13(8-17)$ \\
\hline Panting & $0.01(0.00-0.02)$ & $0.97(0.91-1.00)$ & 0.38 & $46(41-49)$ \\
\hline $\begin{array}{l}\text { Sow has respiratory } \\
\text { problems }\end{array}$ & 0.00 & 1.00 & 1.00 & $46(41-49)$ \\
\hline Sow has diarrhoea & 0.00 & 1.00 & n.a. & $16(3-45)$ \\
\hline Sow has solid faeces & $0.01(0.00-0.08)$ & $0.98(0.80-1.00)$ & n.a. & $5(1-14)$ \\
\hline Sow has skin condition & $0.47(0.04-1.00)$ & $0.02(-0.89-0.86)$ & 0.19 & $43(36-49)$ \\
\hline Sow has shorter tail & $0.23(0.12-0.32)$ & $0.81(0.59-0.96)$ & 0.80 & $46(41-49)$ \\
\hline Sow has vulva lesions & $0.04(0.00-0.10)$ & $0.90(0.78-1.00)$ & 0.66 & $46(41-49)$ \\
\hline
\end{tabular}


Table 4 Inter-observer reliability of eight observers for animalbased parameters in suckling $\mathrm{Su}$ ) and weaned (We) piglets. Values represent mean (minimum-maximum) of observer pair values. $\mathrm{PABAK}=$ prevalence adjusted bias adjusted kappa

\begin{tabular}{llllll}
\hline Parameter & Stage & Prevalence & PABAK & $\begin{array}{l}\text { Kendall's } \\
\text { W }\end{array}$ & $\begin{array}{l}N \text { groups } \\
\text { scored }\end{array}$ \\
\hline $\begin{array}{c}\text { Lame piglets } \\
\text { (scores 1+2) }\end{array}$ & $\mathrm{Su}$ & $0.04(0.00-0.09)$ & $0.93(0.80-1.00)$ & 1.00 & $12(9-14)$ \\
& $\mathrm{We}$ & 0.00 & 1 & 1.00 & 8 \\
$\begin{array}{c}\text { Dirty piglets } \\
\text { (scores 1+2) }\end{array}$ & $\mathrm{Su}$ & $0.06(0.00-0.47)$ & $0.78(0.00-1.00)$ & 0.13 & $13(8-16)$ \\
& $\mathrm{We}$ & $0.50(0.00-0.88)$ & $0.20(-0.75-1.00)$ & 0.45 & 8 \\
$\begin{array}{c}\text { Panting piglets } \\
\text { Respiratory }\end{array}$ & $\mathrm{Su}+\mathrm{We}$ & 0.00 & 1.00 & 1.00 & 20 \\
problems & $\mathrm{Su}$ & 0.00 & 1.00 & 1.00 & $12(815)$ \\
& $\mathrm{We}$ & $0.03(0.00-0.13)$ & $0.88(0.50-1.00)$ & 0.11 & 8 \\
$\begin{array}{c}\text { Diarrhoea } \\
\text { p } \% \text { \% runts }\end{array}$ & $\mathrm{Su}$ & $0.05(00.15)$ & $0.80(0.401 .00)$ & 0.22 & $11(813)$ \\
$\begin{array}{l}\text { Splay leg } \\
\text { piglets }\end{array}$ & $\mathrm{Su}$ & $0.11(0.00-0.13)$ & $0.94(0.75-1.00)$ & 0.88 & 8 \\
\hline
\end{tabular}

0.81-1.00 = almost perfect agreement (Petersen et al. 2004). Spearman $r$ were considered acceptable if $\geq 0.70$.

\section{Farm survey}

Visits in 101 organic pig farms from six EU countries (Austria, Denmark, France, Germany, Italy and Sweden) were performed between March and July 2008. Farms had to be certified organic for at least 2 years and have at least 10 sows. On one French farm, there were only two sows present when the farm was visited. Sow data from this farm were excluded while piglet data were kept.

In France, five farms were jointly assessed by two observers, one of which continued to assess the remaining French farms. All Swedish farms were assessed separately by two observers. In Austria, Denmark, Germany and Italy, farms were visited by one observer per country. During the farm visits, data regarding housing characteristics were recorded through direct observations and farmer interviews using standardised questionnaires.

Due to unsatisfactory inter-observer reliability, dirtiness and skin condition in sows, as well as dirtiness and presence of runts in weaned piglets are not presented. Injury data from Denmark were also excluded due to disagreement with the Danish observer (negative PABAK and correlations with almost all other observers). Data on faecal consistency in sows are not presented because faeces could only be scored in $49 \%$ of sows. Finally, some parameters could not be assessed in some farms due to lack or insufficient numbers of animals.
Overall, each of the parameters was assessed in 84 to 100 farms (Table 6).

Lactating and gestating sows were combined for analysis in order to achieve greater samples per farm. We calculated prevalences for each parameter and farm, which were based on the number of sows or piglet groups, respectively (sum of positive scores divided by number of sows or piglet groups scored, respectively).

The associations between farm prevalences of selected parameter pairs were investigated using Spearman rank correlations, while the associations at animal (sows) or group (piglets) level were investigated using $\chi^{2}$ tests.

\section{Results}

Inter-observer reliability

\section{Sow scores}

None of the observers detected metritis, diarrhoea or respiratory problems in sows during the IOR test (Table 3), and six parameters had a prevalence of $<10 \%$. Pairwise agreement between observers was almost perfect for 10 parameters (mean PABAK $>0.80$ ), yet agreement across all observers $(W)$ did not match pairwise agreement in parameters with prevalences of 1 to $3 \%(W<0.4)$. For four parameters (thin sows, injuries on the legs, injuries on the anterior and hind parts of the body), pairwise as well as overall agreement was 
moderate to substantial $(0.5<$ mean $\mathrm{PABAK}<0.7$; $0.5<W<0.8)$. Observers did not agree on skin condition and dirtiness (mean PABAK $<0.3$ and smallest PABAK $\leq 0$ ). Spearman rank correlation coefficients for agreement on lesion numbers in the respective body regions ranged from -0.02 to 0.84 in the body regions anterior and legs $($ mean $=0.47)$, and from 0.04 to 0.91 for hind quarters (mean $=0.52 ; 8$ observers, 21 observer pairs).

\section{Piglet scores}

None of the observers detected lameness in weaned piglets, panting in both suckling and weaned piglets, or respiratory problems or splay leg in suckling piglets (Table 4). In the remaining parameters, average prevalence was $<15 \%$, except for dirtiness in weaned piglets. Pairwise observer agreement was almost perfect for eight parameters (PABAK $\geq 0.80$ ), yet again $W$ were low in several parameters with low prevalence (e.g. respiratory problems and diarrhoea in weaned piglets). Observers did not agree on dirtiness and on presence of runts in weaned piglets (smallest PABAK $\leq 0$; Table 4).

Animal-based parameters in the survey

\section{Herd characteristics}

Herd size ranged from 10 to 680 sows per farm with an average of 75 sows (Table 5). Pigs in Austria and Germany were predominantly kept indoors ( $>75 \%$ of farms) while pigs in Denmark and Italy were predominantly kept outdoors ( $>90 \%$ of farms). Swedish farms were characterised by seasonal housing with (partly) outdoor housing in summer and indoor housing in winter, and by more frequent group suckling. Weaner piglets were most often kept indoors except in Italy. For more details on farm characteristics, see Sundrum et al. (2011).

\section{Sow scores}

Animal-based parameters were assessed in 7 to 59 sows per farm on 84 to 100 farms in total (Table 6). The most frequent problem found in sows was thinness (poor body condition; median farm prevalence $18.8 \%$ ), followed by injuries on anterior and hind body parts (12.5 and $7.9 \%$, respectively, Fig. 1). The median prevalences of many parameters were $0 \%$, yet most parameters showed a high variability between farms (Fig. 1). Prevalences of injuries anterior, hind and legs were correlated with each other $(r \geq 0.58, p<0.001$, $N=84$ farms; Table 7), as was prevalence of vulva lesions with prevalence of injuries on the anterior or hind parts of the body $(r \geq 0.40, p<0.001, N=84)$.

\section{Piglet scores}

Overall, between 1 and 12 (median=7) groups of suckling piglets were assessed per farm on 91 to 95 farms in total. As $91 \%$ of groups consisted of 1 litter and the remainder consisted of 2 to 10 litters, the median number of litters assessed per farm was 8 (range 1 to 32 ). The median prevalence in terms of groups affected per farm was $0 \%$ for all parameters but dirtiness, for which it was $10 \%$. Farm prevalence ranged from 0 to $33 \%$ for respiratory problems, 0 to $50 \%$ for $\geq 1$ splay leg piglet in group, and 0 to $100 \%$ for $\geq 1$ lame piglet in group, diarrhoea, and $>50 \%$ dirty piglets in group (Fig. 2). Panting was not seen in suckling piglets on any farm. Absence of scouring was significantly associated with absence of respiratory problems at group level $\left(\chi^{2}=6.36, p=0.012, N=570\right)$ but not at farm level $\left(r_{\text {Spearman }}=0.10, p=0.350, N=92\right)$.

The median number of weaned piglet groups assessed per farm was 2 (range 1 to 13), and the median number of weaned piglets scored per farm was 79 (diarrhoea $=76$, respiratory problems $=78$; range for all parameters $=3$ to 1,050 ). The median prevalence in terms of groups affected per farm was $0 \%$ with a range of 0 to $100 \%$ for all parameters. Prevalences of diarrhoea and respiratory problems were highly variable (Fig. 3). Absence of scouring was significantly associated with absence of respiratory problems at group level $\left(\chi^{2}=21.21, p<0.001, N=224\right)$ and at farm level $\left(r_{\text {Spearman }}=0.39, p<0.001, N=91\right)$.

\section{Discussion}

Inter-observer reliability

At the start of the present project, it was assumed that agreement between observers would be satisfactory after sufficient training, as was common opinion at the time. After increasing discussion about the topic, we decided to test agreement after data collection and to exclude parameters with insufficient agreement from analysis. 
Table 5 Basic characteristics of farms from the survey. Multiple answers were possible regarding husbandry of animal groups [\% of farms unless otherwise specified]

\begin{tabular}{|c|c|c|c|c|c|c|c|}
\hline Parameter & Austria & Denmark & France & Germany & Italy & Sweden & Total \\
\hline$n$ observers & 1 & 1 & 2 & 1 & 1 & 2 & 8 \\
\hline$n$ farms & 16 & 16 & 20 & 20 & 16 & 13 & 101 \\
\hline Herd size (no. of sows) ${ }^{a}$ & $43(10,106)$ & $162(20,575)$ & $36(12,80)$ & $104(18,680)$ & $38(15,280)$ & $66(15,175)$ & $75(10,680)$ \\
\hline Agricultural area in use (ha) ${ }^{a}$ & $46(12,145)$ & $129(16,450)$ & $59(19,109)$ & $103(17,370)$ & $63(8,214)$ & $153(30,320)$ & $89(8,450)$ \\
\hline Group suckling ${ }^{\mathrm{b}}$ & 56.0 & 44.0 & 30.0 & 65.0 & 38.0 & 92.0 & 52.0 \\
\hline \multicolumn{8}{|c|}{ Husbandry ( $\%$ of farms) gestating sows ${ }^{b}$} \\
\hline Indoor & 94.0 & 25.0 & 65.0 & 75.0 & 6.3 & 77.0 & 57.0 \\
\hline Outdoor & 6.3 & 100.0 & 60.0 & 15.0 & 94.0 & 38.0 & 51.0 \\
\hline Seasonal & 0.0 & 6.3 & 0.0 & 0.0 & 0.0 & 69.0 & 9.9 \\
\hline \multicolumn{8}{|l|}{ Lactating sows ${ }^{b}$} \\
\hline Indoor & 94.0 & 0.0 & 35.0 & 75.0 & 6.3 & 92.0 & 50.0 \\
\hline Outdoor & 6.3 & 100 & 70.0 & 15.0 & 100 & 15.0 & 51.0 \\
\hline Seasonal & 0.0 & 0.0 & 5.0 & 0.0 & 0.0 & 23.0 & 4.0 \\
\hline \multicolumn{8}{|l|}{ Weaned piglets ${ }^{b}$} \\
\hline Indoor & 94.0 & 56.0 & 65.0 & 70.0 & 19.0 & 69.0 & 62.0 \\
\hline Outdoor & 6.3 & 44.0 & 30.0 & 15.0 & 81.0 & 46.0 & 36.0 \\
\hline Seasonal & 0.0 & 0.0 & 0.0 & 0.0 & 0.0 & 62.0 & 7.9 \\
\hline
\end{tabular}

${ }^{\mathrm{a}}$ Mean (min, max)

${ }^{\mathrm{b}}$ Multiple answers were possible

For numerous parameters (metritis, respiratory problems and diarrhoea in sows, panting, respiratory problems and splay legs in suckling piglets, lameness and panting in weaned piglets), prevalence recorded in the reliability test was zero for all observers. As observers thus agreed on problem absence we kept those parameters in the survey results, even though we could not test their agreement on presence.

The low agreement achieved in the present study for skin condition and dirtiness can be attributed to misunderstandings regarding the definitions of these parameters. One of the main issues regarding skin condition was the categorisation of sunburn. Regarding dirtiness, the Welfare Quality ${ }^{\circledR}$ protocol states that only manure/faeces on the body should be considered when scoring the animals. Discussion between observers after completing the assessment showed that some observers did not differentiate between mud and manure. This misinterpretation of the protocol might explain the high variability between observers.

Out of the measures of animal health and welfare used in the present study, only lameness, skin lesions and body condition scoring have been tested for inter-observer agreement in other studies. Observer agreement for lameness in sows in the presentstudy (mean PABAK 0.95) was higher than the agreement previously reported by Geverink et al. (2009): Spearman $r>0.7$ for two observer pairs and $0.4-0.7$ for four observer pairs. Similarly, agreement for lameness in suckling and weaned piglets (mean PABAK $=0.93$ and 1.00 , respectively) was higher than the agreement for lameness in fattening pigs (mean $\mathrm{PABAK}=0.51$ ) reported by Petersen et al. (2004). Observer correlation for skin lesion counts in the present study (mean $r_{\mathrm{s}}$ anterior and legs $=0.47, r_{\mathrm{s}}$ hind quarter $\left.=0.52\right)$ was lower than in other studies $\left(r_{\mathrm{s}}\right.$ overall count $=0.8$ to 0.9 in Burfoot et al. 1995; $r_{\mathrm{s}}$ overall $=0.9$ in Turner et al. 2006). This might be due to the larger number of observers with varying background involved in the present study. Unfortunately, the IOR results for body condition scoring from Charette et al. (1996) are incompatible with our calculations.

\section{Animal-based parameters}

Taking into account the number of organic sows present in the various countries in 2006 (Früh et al. 2011) and assuming that the increase between 2006 and 2008 was 
Table 6 Distribution of farm prevalences of animal-based parameters for lactating and gestating sows combined

\begin{tabular}{llll}
\hline Parameter & $\begin{array}{l}n \\
\text { farms }\end{array}$ & $\begin{array}{l}n \text { sows scored } \\
\text { per farm median } \\
(\text { min, max })\end{array}$ & $\begin{array}{l}\text { Prevalence } \\
{[\%] \text { median }} \\
(\text { min, max })\end{array}$ \\
\hline$>1$ injury anterior ${ }^{\text {a }}$ & 84 & $25(7,41)$ & $12.5(0,66.7)$ \\
$>1$ injury hind ${ }^{\text {a }}$ & 84 & $25(7,41)$ & $7.9(0,50)$ \\
$>1$ injury legs ${ }^{\text {a }}$ & 84 & $25(7,41)$ & $0(0,19.4)$ \\
Fat $(\mathrm{BCS}>3)$ & 100 & $32(7,59)$ & $4.9(0,50)$ \\
Thin $(\mathrm{BCS}<3)$ & 100 & $32(7,59)$ & $18.8(0,81)$ \\
Lame & 100 & $30(5,45)$ & $0(0,50)$ \\
Mastitis ${ }^{\text {b. c }}$ & 95 & $9(1,15)$ & $0(0,33.3)$ \\
Metritis ${ }^{\text {b. d }}$ & 94 & $9(1,24)$ & $0(0,33.3)$ \\
Panting & 100 & $32(7,45)$ & $0(0,13.9)$ \\
Respiratory problems & 100 & $32(7,45)$ & $0(0,5.1)$ \\
Shorter tail & 100 & $31(7,45)$ & $17.1(0,100)$ \\
Vulva lesions & 100 & $31(7,59)$ & $3.5(0,42.9)$ \\
\hline
\end{tabular}

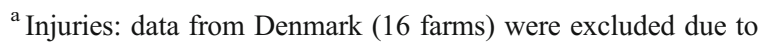
unsatisfactory IOR

${ }^{\mathrm{b}}$ Scored in lactating sows only

${ }^{\mathrm{c}}$ Could not be scored on one French, three Italian and one Swedish farm

${ }^{\mathrm{d}}$ Could not be scored on one Austrian, one French, three Italian and one Swedish farm

less than $10 \%$, the farms included in the present study housed 15 to $20 \%$ of organic sows in Austria, France and Germany, and more than $50 \%$ of the organic sows in Denmark and Sweden (data for Italy not available). Therefore, the results of the present study can be considered as a good overview of the situation of organic sows and piglets in the various countries involved, especially in Denmark and Sweden.

\section{Sow scores}

Injury scoring in sows was modified from the Welfare Quality ${ }^{\circledR}$ protocol in order to be more feasible, and to obtain quantitative information instead of scores. Injury prevalences found (anterior $12.5 \%$, hindquarter $7.9 \%$, legs $0 \%$ ) were lower than prevalences reported in comparable publications. Indeed, $15 \%$ of sows were affected by lesions in 82 organic or conventional farms from the UK and The Netherlands (Scott et al. 2009), $37.6 \%$ of sows in 55 conventional farms from Austria (Leeb et al. 2001) and $44 \%$ of sows in 7 organic or label farms from northern Germany (Winckler et al. 2001). The prevalence of vulva lesions in the present study $(3.5 \%)$ was also lower than in other studies $(9 \%$ in Scott et al. 2009 and Winckler et al. 2001; $16 \%$ in Leeb et al. 2001). Injuries arise from aggression, either during fighting when unfamiliar pigs are mixed, or when the pigs compete for food and other resources (Fraser et al. 1995). Higher prevalences of anterior injuries as found in the present study typically arise from reciprocal fighting, for example during regrouping (Rundgren and
Fig. 1 Farm prevalences of sow parameters scored on 84 (lesions), 94 (metritis), 95 (mastitis) or 100 (rest) farms in six European countries. Boxes extend from first to third quartile and include the median (horizontal line). Whiskers extend to $1.5 \times$ inter-quartile range, with values outside this range marked as stars

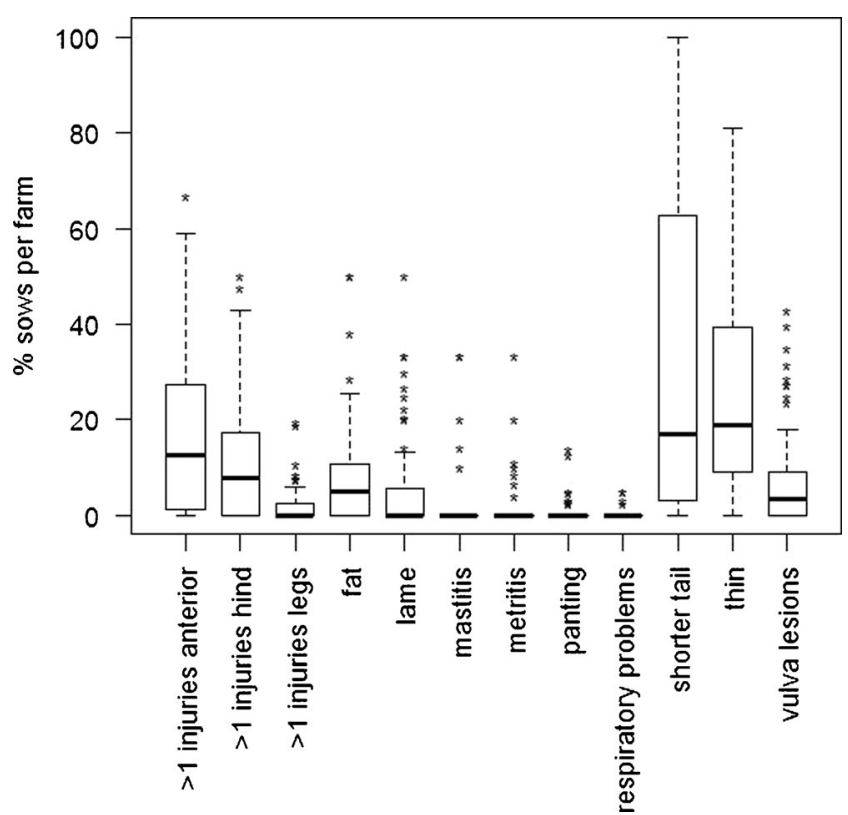



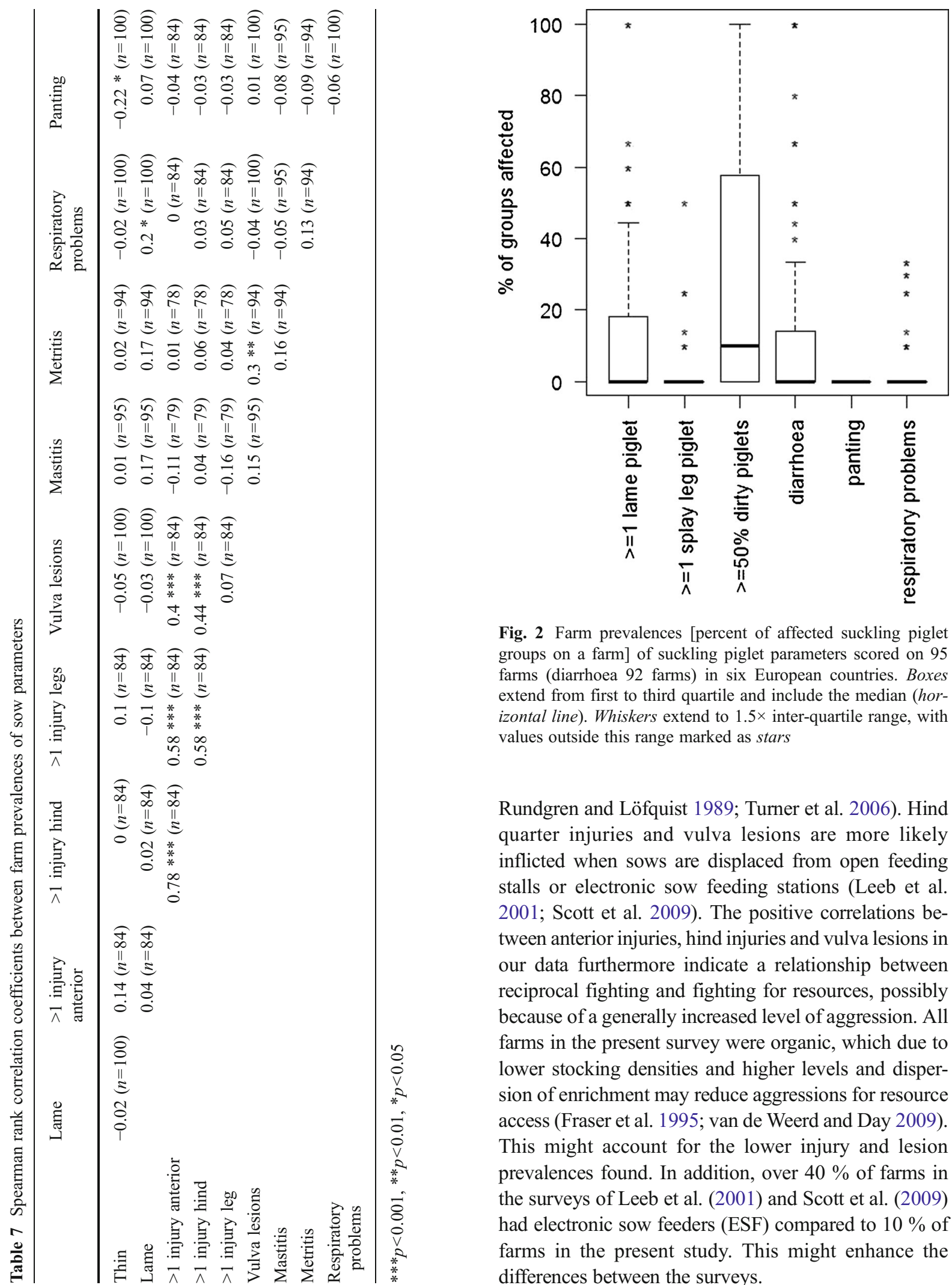

Fig. 2 Farm prevalences [percent of affected suckling piglet groups on a farm] of suckling piglet parameters scored on 95 farms (diarrhoea 92 farms) in six European countries. Boxes extend from first to third quartile and include the median (horizontal line). Whiskers extend to $1.5 \times$ inter-quartile range, with values outside this range marked as stars

Rundgren and Löfquist 1989; Turner et al. 2006). Hind quarter injuries and vulva lesions are more likely inflicted when sows are displaced from open feeding stalls or electronic sow feeding stations (Leeb et al. 2001; Scott et al. 2009). The positive correlations between anterior injuries, hind injuries and vulva lesions in our data furthermore indicate a relationship between reciprocal fighting and fighting for resources, possibly because of a generally increased level of aggression. All farms in the present survey were organic, which due to lower stocking densities and higher levels and dispersion of enrichment may reduce aggressions for resource access (Fraser et al. 1995; van de Weerd and Day 2009). This might account for the lower injury and lesion prevalences found. In addition, over $40 \%$ of farms in the surveys of Leeb et al. (2001) and Scott et al. (2009) had electronic sow feeders (ESF) compared to $10 \%$ of farms in the present study. This might enhance the differences between the surveys. 


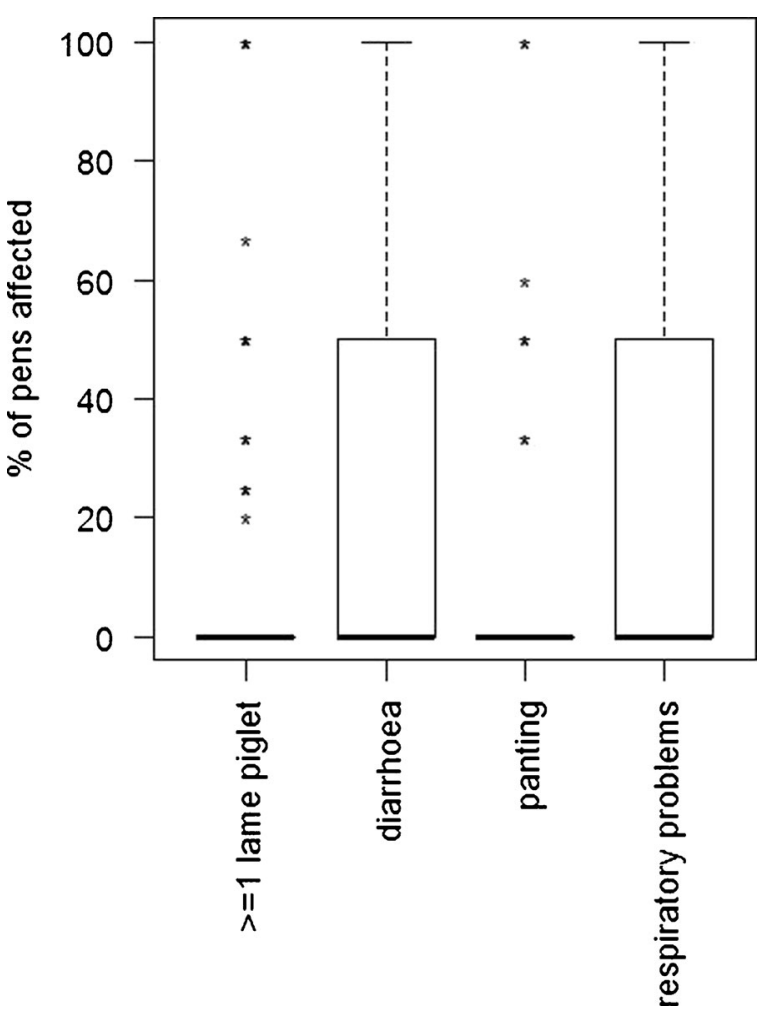

Fig. 3 Farm prevalences [percent of weaner groups affected on a farm] of weaned piglet parameters scored on 95 farms (diarrhoea 91 farms, respiratory problems 94 farms) in six European countries. Boxes extend from first to third quartile and include the median (horizontal line). Whiskers extend to $1.5 \times$ interquartile range, with values outside this range marked as stars

The high variability of injury/lesion prevalences between farms independently of farming system makes injuries a useful indicator for welfare assessment protocols as well as farm improvement schemes. The good correlation between scores on different areas on the body might allow focussing on high impact areas like shoulders, hind and vulva.

The prevalence of $19 \%$ thin sows in the present study is much higher than in other studies $(6 \%$ in the survey of Winckler et al. 2001; $5 \%$ of sows either thin or fat in the survey of Scott et al. 2009). This suggests higher difficulties for organic farmers to meet the nutritional requirements of sows, even though Day et al. (2003) did not find thinness to be a problem on nine organic farms in the UK. However, direct comparison of surveys may be difficult. The ratio of pregnant and lactating sows included in each survey has a major effect on the observed prevalence of thin sows. The fact that the minority of farmers in the present study used body condition scoring to adjust feeding (Sundrum et al. 2011) may have contributed to poor body condition. Due to its high variability between farms and to its relevance for reproductive performance and animal welfare, body condition should be included in welfare and farm improvement assessment protocols.

Sow lameness seems to be a lower problem on organic farms than on conventional ones. Whereas average lameness prevalence in the present study as well as in that of Day et al. (2003) was $0 \%$, surveys on conventional farms reported 9,17 or $20 \%$ of lame sows (Heinonen et al. 2006; KilBride et al. 2009; Geverink et al. 2009, respectively). This might be due to differences in housing systems, as KilBride et al. (2009) found slatted flooring to be a major risk factor for lameness. Unlike expected, there was no significant correlation between lameness and low body condition in sows, probably because correlations were calculated at farm level. It would be interesting to investigate whether impaired mobility impacts body condition through reduced feed access at animal level. Even if lameness did not pose a general problem among the organic farms in the present survey, it varied between farms and posed a considerable problem on some farms (maximum farm prevalence $50 \%$ ). Therefore, it is a useful indicator for welfare assessment as well as for farm improvement schemes, in addition to being very relevant for welfare.

Prevalence of mastitis and metritis was low, probably mainly due to the short duration of these diseases, which reduces chances to record them during a farm visit. A more valid approach might be to indirectly detect them by their negative consequences on piglet survival and growth during the first weeks of lactation (Pedersen et al. 2006).

Panting was observed at low prevalence. This is not surprising, as it is a short-term reaction to elevated ambient temperature or to fever, and hence can be detected only during short periods when ambient temperature is elevated or when animals are suffering from disease. It was observed on two Austrian, one Danish, two German, three Italian and one Swedish farm, with the highest prevalence on the Italian farms. Visits to those farms took place between April and June 2008. Despite the strong relation to ambient temperature (and the resulting validity implications), presence of panting should be noted during welfare assessment because it indicates that animals are suffering from heat or disease and hence their welfare is reduced. 
Prevalences of respiratory problems as well as digestive disorders were also were very low. This might in part be explained by accessibility problems. Sneezing and coughing are difficult to detect when animals are outdoor, which was the case for about half of the sows. However, should such problems be detected, they are welfare relevant indicators and should thus be assessed.

In view of the ban on routine tail docking in organic sows (Commission Regulation EC no. 889/2008), there were surprisingly many sows with a short tail $(17 \%)$. The most likely explanation for this lies in the low availability of organic gilts on the market. More than $50 \%$ of the farmers in the survey bought gilts instead of raising their own replacements (Sundrum et al. 2011), and most of those will have been conventional which are usually tail docked (EFSA 2007).

\section{Piglet scores}

Regarding suckling and weaned piglets, median prevalence of groups with lame piglets is low, with high variability between farms, likewise for the prevalences of respiratory problems and diarrhoea. Unfortunately, we could not find any publications to compare our results with.

It should be noted, that a group-level scoring system was used for the three abovementioned parameters and an average of five groups was scored per farm. This results in discontinuous values (e.g. no possible value between 0 and $20 \%$ when five groups are observed). Moreover, the scoring system did not allow adjusting for group size. Sneezing, coughing and diarrhoea are difficult to detect when animals are outdoors, which was the case for about half of the suckling piglets and about one third of weaners. In addition, lameness in piglets was also difficult to assess outdoors because piglets can be hidden by vegetation and generally keep a greater distance to observers. Panting was observed rarely in weaners and never in suckling piglets. As piglets need higher ambient temperatures than sows, the panting observed in weaners was probably associated with respiratory problems. The inclusion of panting in a piglet assessment protocol is questionable, whereas the other parameters should be included while bearing their restrictions in mind.

\section{Farm assessment protocol}

To our knowledge, the present study is the second application of indicators from the Welfare Quality ${ }^{\circledR}$ protocol to organic pigs. Results from an assessment of sows in various housing and production systems can be found in Scott et al. (2009). All problems we encountered during farm assessment or observer agreement testing are not specifically related to organic farming but to the housing system. This has also been reported by Scott et al., who pointed out the higher difficulties to collect data on animals kept outdoors, which can indeed be applied in both organic and conventional pig production systems.

Mastitis, metritis, diarrhoea and respiratory problems could also be inferred from farm records, yet this approach has its own drawbacks. Evaluating farm records is time-consuming and, on some farms, records are incomplete. Furthermore, records have limited validity, due to restriction in allopathic treatments through organic regulation (Commission Regulation EC no. $889 / 2008$ 2008) and the dependence of treatment incidence on both, disease incidence and farmer reaction, which makes records ambivalent. Respiratory problems could also be recorded as gross pathological findings in the respiratory system at the abattoir, yet this requires higher logistic and work input than including it in a farm visit.

\section{Conclusions}

The assessment of clinical measures of animal health and welfare does not necessarily achieve satisfactory inter-observer agreement. Therefore, intensive training and inter-observer agreement testing should be included and reported in all multi-observer studies. In sows, injuries including vulva lesions, body condition and lameness appear to be useful indicators for health and welfare of (organic) pigs, which should be integrated in welfare assessment protocols and farm improvement schemes. Thinness appears to be a considerable problem in organic sows and farmers should use body condition of their sows to adjust feeding. In piglets, score definitions should integrate the number of animals scored (e.g. group prevalence). Unlike lameness, respiratory problems, diarrhoea and runts, panting does not seem to be a useful indicator in piglets.

Acknowledgments The study was part of the ERA-net CORE Organic project COREPIG (http://corepig.coreportal.org). The authors wish to thank all national funders for their financial support. We would also like to thank Aude Bourgoin and Lene Hegelund for collecting data on farms in France and Denmark as well as all the farmers who participated in the present study. Where required, 
the national sub-projects were approved according to the national regulations on Ethical approval for research in animals (Sweden: local Ethical Committee for Laboratory Animals in Gothenburg (Göteborgs djurförsöksetiska nämnd, Diary no. 45-2008)).

\section{References}

Bonde M, Sorensen JT (2006) Animal health and welfare in organic European pig production: state of the art and challenges for the future, based on a Northwestern European questionnaire survey. Proc Eur Jt Org Congr 2006:562-563, Odense (DK)

Bonde M, Hegelund L, Sørensen JT (2006) Forskellige sundhedsproblemer hos økologiske henholdsvis konventionelle indendørs slagtesvin (in Danish). Forskningsnytt om Økologisk Landbruk i Norden 1:8-9

Burfoot A, Kay RM, Corning S (1995) A scoring method to assess damage caused by aggression between sows after mixing. Proc Brit Soc Anim Sci, Annual Meeting: 196-197

Charette R, Bigras-Poulin M, Martineau G-P (1996) Body condition evaluation in sows. Livest Prod Sci 46:107-115

Commission Regulation EC no. 889/2008 (2008) Laying down detailed rules for the implementation of Council Regulation (EC) No 834/2007 on organic production and labelling of organic products with regard to organic production, labelling and control. Official Journal of the European Union, L 250, p 84

Day JEL, Kelly H, Martins A, Edwards SA (2003) Towards a baseline assessment of organic pig welfare. Anim Welf 12:637-641

Ebke M, Sundrum A (2005) Qualitätssicherung in der ökologischen Schweinemast (in German) [Quality assurance in organic pig finishing]. Beiträge zur 8. Wissenschaftstagung zum Ökologischen Landbau, 01. -04. 03. 2005, Kassel (DE):337340

EFSA (2007) Scientific Opinion of the Panel on Animal Health and Welfare on a request from Commission on the risks associated with tail biting in pigs and possible means to reduce the need for tail docking considering the different housing and husbandry systems. EFSA J 611:1-100

Fraser D, Kramer DL, Pajor EA, Weary DM (1995) Conflict and cooperation: sociobiological principles and the behaviour of pigs. Appl Anim Behav Sci 44:139-157

Früh B, Bochicchio D, Edwards S, Hegelund L, Leeb C, Heinonen M, Maupertuis F, Sundrum A, Werne S, Wiberg S (2011) Description of organic production systems in Europe in 2007. In: Edwards S (Ed) Knowledge synthesis: animal health and welfare in organic pig production-Final Report COREPIG. http://orgprints.org/ $18419 /$

Geverink NA, Meuleman M, van Nuffel A, van Steenbergen L, Hautekiet V, Vermeulen K, Lammens V, van Reenen CG, Tuyttens FAM (2009) Repeatability of lameness score measured on farm. In: Forkman B, Keeling L (ed) Assessment of animal welfare measures for sows, piglets and fattening pigs. Welfare Quality Reports No. 10:73-78

Harper GC, Makatouni A (2002) Consumer perception of organic food production and farm animal welfare. Brit Food J 104:287-299

Heinonen M, Oravainen J, Orro T, Seppä-Lassila L, Ala-Kurikka E, Virolainen J, Tast A, Peltoniemi OAT (2006) Lameness and fertility of sows and gilts in randomly selected loosehoused herds in Finland. Vet Rec 159:383-387

Heldmer E, Lundeheim N, Robertsson JÅ (2006) Sjukdomsfynd hos ekologiskt uppfödda grisar (in Swedish). Svensk Veterinärtidning 13:13-19

KilBride AL, Gillman CE, Green LE (2009) A cross-sectional study of the prevalence of lameness in finishing pigs, gilts and pregnant sows and associations with limb lesions and floor types on commercial farms in England. Anim Welf 18:215-224

Leeb B, Leeb C, Troxler J, Schuh M (2001) Skin lesions and callosities in group-housed pregnant sows: animal-related welfare indicators. Acta Agr Scand A: Anim Sci Suppl 30:82-87

MAFF (1998) Condition scoring of pigs. MAFF Publications, London

McGlone JJ (1985) A quantitative ethogram of aggressive and submissive behaviors in recently regrouped pigs. J Anim Sci 61:559-565

Meagher RK (2009) Observer ratings: validity and value as a tool for animal welfare research. Appl Anim Behav Sci 119:1-14

Pedersen LJ, Jørgensen E, Heiskanen T, Damm BI (2006) Early piglet mortality in loose-housed sows related to sow and piglet behaviour and to the progress of parturition. Appl Anim Behav Sci 96:215-232

Petersen HH, Enoe C, Nielsen EO (2004) Observer agreement on pen level prevalence of clinical signs in finishing pigs. Prev Vet Med 64:147-156

Rundgren M, Löfquist I (1989) Effects on performance and behavior of mixing 20-kg pigs fed individually. Anim Prod 49:311-315

SAS Institute Inc. (2008) SAS OnlineDoc ${ }^{\circledR}$ 9.1.3, http://support. sas.com/onlinedoc/913/docMainpage.jsp. Accessed 29 May 2012

SAS Institute Inc. (2009). Computer estimates and tests of agreement among multiple raters (MAGREE), http:// support.sas.com/kb/25/006.html. Accessed 29 May 2012

Scott K, Binnendijk GP, Edwards SA, Gu JH, Kiezebrink MC, Vermeer HM (2009) Preliminary evaluation of a prototype welfare monitoring system for sows and piglets (Welfare Quality ${ }^{\circledR}$ project). Anim Welf 18:441-449

Sundrum A, Goebel A, Bochicchio D, Bonde M, Bourgoin A, Cartaud G, Dietze K, Dippel S, Gunnarsson S, Hegelund L, Leeb C, Lindgren K, Lubac S, Prunier A, Wiberg S (2011) Epidemiological study concerning the characteristics of organic pig farming in selected European countries. In: Sundrum A (ed) Final Report COREPIG. http:// orgprints.org/18428/

Turner SP, Farnworth MJ, White IMS, Brotherstone S, Mendl M, Knap P, Penny P, Lawrence AB (2006) The accumulation of skin lesions and their use as a predictor 
of individual aggressiveness in pigs. Appl Anim Behav Sci 96:245-259

van de Weerd HA, Day JEL (2009) A review of environmental enrichment for pigs housed in intensive housing systems. Appl Anim Behav Sci 116:1-20

Welfare Quality ${ }^{\circledR}(2009)$ Welfare Quality ${ }^{\circledR}$ Assessment protocol for pigs (sows and piglets, growing and finishing pigs) Welfare Quality ${ }^{\circledR}$ Consortium, Lelystad, The Netherlands
Winckler C, Bühnemann A, Seidel K, Küfmann K, Fenneker A (2001) Label pig production and organic pig farming - a pilot study on housing and welfare related parameters in sows. Proc. CIGR Symposium Animal Welfare Considerations in Livestock Housing Systems, Szklarska Poreba, Poland, pp 479-490

Zanoli R, Naspetti S (2002) Consumer motivations in the purchase of organic food: a means-end approach. Brit Food J 104:643-653 